\title{
Dendritic Boundary Corrosion of AA2198 Weld Using Fiber Laser Welding with Al-Cu Filler Wire
}

\author{
Jun-Xia Lu ${ }^{1} \cdot$ Ling Chang ${ }^{1} \cdot$ Shi-Kai Wu ${ }^{1} \cdot$ Shi-Kun Yin ${ }^{1}$
}

Received: 15 August 2017 / Revised: 7 December 2017 / Published online: 29 December 2017

(C) The Chinese Society for Metals and Springer-Verlag GmbH Germany, part of Springer Nature 2017

\begin{abstract}
The microstructures and corrosion behaviors of AA2198-T851 alloy and weld were analyzed under corrosive conditions. Weld was formed using an innovative fiber laser welding process with AA2319 Al-Cu filler wire. The metallurgic morphology and distribution of the chemical compositions were determined using imaging techniques such as optical micrograph, scanning electron micrograph, high-resolution transmission electron microscopy, energy-dispersive X-ray spectrometry and X-ray diffraction. Corrosion was evaluated using an immersion test and electrochemical impedance spectroscopy in 3.5\% $\mathrm{NaCl}$ solution at room temperature. Results indicate that the parent alloy suffered from pitting corrosion during the initial 4-h immersion which was caused by the inhomogeneous distribution of its chemical components and the different intermetallics formed during the rolling process. The weld experienced dendritic boundary corrosion under the same conditions due to the addition of the Al-Cu filler and rapid solidification during laser welding, which led to the precipitates $\mathrm{Cu}$ enrichment along the grain boundary. When a welding joint was immersed in the solution for 5 days, a big crack was observed across the center of the weld. In comparison, there was good corrosion resistance in the heataffected zone with a compact protective film.
\end{abstract}

Keywords 2198 Aluminum alloy $\cdot$ Fiber laser welding · Dendritic boundary corrosion $\cdot$ Al-Cu filler wire

\section{Introduction}

The third-generation Al-Li alloy, 2198, has been developed from $\mathrm{Al}-\mathrm{Cu}-\mathrm{Mg}$ alloy by adding a small proportion of the light metal $\mathrm{Li}$ and decreasing the $\mathrm{Cu}$ content. The addition of $1 \% \mathrm{Li}$ to the $\mathrm{Al}$ alloy reduces the alloy density by $3 \%$ and increases the elastic modulus by $6 \%[1,2]$, while significantly improving the fatigue intensity. In addition to $\mathrm{Li}, \mathrm{AA} 2198$ is introduced to lower the $\mathrm{Cu}$ content of the $2195 \mathrm{Al}-\mathrm{Li}$ alloy from about 4 to $3 \%$ to reduce weight and significantly increase elongation. The combination of these properties and the resultant $10 \%$ lower density and $10 \%$ higher modulus than conventional aluminum alloys make the AA2198 Al-Cu-Li alloys to be

Available online at http://link.springer.com/journal/40195

Jun-Xia Lu

junxialv@bjut.edu.cn

1 Institute of Laser Engineering, Beijing University of Technology, Beijing 100126, China more attractive for applications in aircraft and other aerospace structures.

In addition to low density and high intensity in 2198 aluminum alloys, cost savings of up to $50 \%$ may be possible with alternate design strategies using integral and welded structures to replace build-up structures. Compared to other grades of age-hardenable aluminum alloy, AA2198 has better weldability, but it also suffers from lower welded joint strength. Laser welding, as a novel fabrication method, can decrease heat input, and it involves rapid solidification of the alloy with a very small microstructure ( $<10 \mu \mathrm{m}$ diameter) with matching filler can be attained, which is a very favorable mechanical welding property for joints. Rapid solidification during laser welding also induces the inhomogeneous distribution of microstructures and creates unstable phases, so the corrosion resistance of a joint may be deteriorate due to microsegregation, unfavorable phase content, the presence of microporosities and cracks and also vaporization. The presence of filler wire induces the microstructural and compositional differences between the weld and base metal, and also induces the Galvanic cell in the corrosive liquid. Our study found that 
the joint strength of welded AA2198 with Al-Si filler wire only reaches about $65 \%$ of the strength of the parent alloy [3]. There is uniform corrosion of the weld due to the addition of $\mathrm{Si}$, which facilitates $\mathrm{Cu}$ scattering [4]. In order to further increase the joint strength for providing a greater filler wire choice for industrial welding applications, we tried to use the $\mathrm{Al}-\mathrm{Cu}$ filler wire. According to $\mathrm{Al}-\mathrm{Cu}$ and Al-Si binary alloy phase diagrams [5], the solid solution with more $\mathrm{Cu}(5.7 \%)$ than $\mathrm{Si}(1.65 \%)$ in $\alpha-\mathrm{Al}$ can expect to be beneficial to improve the joint strength by the solid solution strengthening effect. In addition, the higher $\mathrm{Cu}$ content in $\mathrm{Al}-\mathrm{Cu}$ filler than the parent alloy will also promote the compatibility between the parent metal and the filler wire and therefore will help to reduce defects, such as cracks and pores. Our previous study found that the tensile strength of welding joints in AA2198 with Al-Cu filler wire was about $57 \%$ as strong as the parent alloy [6]. This study investigates the corrosion behavior of AA2198 with $\mathrm{Al}-\mathrm{Cu}$ filler wire using high-power fiber laser welding.

\section{Experimental}

A 2-mm-thick 2198-T851 Al-Cu-Li alloy sheet and AA2319 Al-Cu alloy filler wire with a diameter of $1.2 \mathrm{~mm}$ were used in this study. Their chemical compositions are shown in Table 1.

Prior to welding, the surfaces of the AA2198-T851 plate were polished by abrasive paper and degreased by acetone. Welding experiments were carried out with a YLS-6000 Fiber Laser (IPG Photonics) operating at $3 \mathrm{~kW}$, as shown in Fig. 1. Laser conditions (power and speed) were optimized depending on the focal lens used. The welding speed and filler wire input speed were 3 and $2 \mathrm{~m} / \mathrm{min}$, respectively. The diameter of the laser beam spot was focused at $1 \mathrm{~mm}$. An argon shielding gas with flux of $10 \mathrm{~L} / \mathrm{min}$ was used to protect the heated surface from oxidation.

The microstructures of the weld and parent alloy were studied by an Olympus optical micrograph, a Hitachi S3400N scanning electron micrograph equipped with a Bruker 5010 energy-dispersive X-ray spectrometer (EDX) and a JEOL-2010 high-resolution transmission electron microscope (HRTEM). For the HRTEM studies, plates were mechanically thinned to $0.2-0.3 \mathrm{~mm}$ by manually polishing both surfaces of the disks with 240- to 600-grit abrasive papers. The 3-mm-thick disks were cut and then

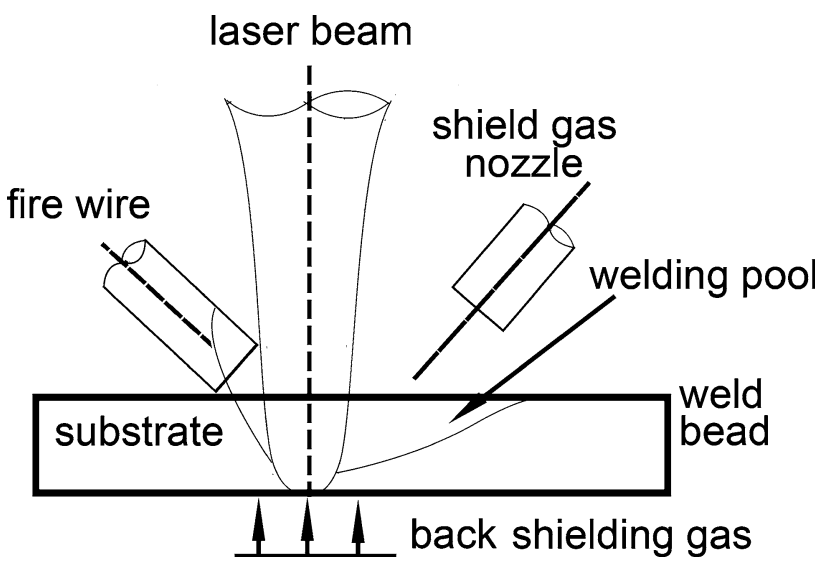

Fig. 1 Schematic illustration of the laser welding experimental setup

electropolished in a $30 \% \mathrm{HNO}_{3}$ plus $70 \%$ methanol solution at -20 to $-30{ }^{\circ} \mathrm{C}$ and at $20 \mathrm{~V}$ in a Model 110 TwinJet Electropolisher. The procedure produced sufficiently large, thin regions to facilitate HRTEM studies. The phase compositions of the parent alloy, weld and HAZ were characterized by $\mathrm{X}$-ray diffraction $\left(\mathrm{Cu} K_{\alpha}\right.$ radiation). Because the weld and HAZ regions of the joints are very narrow, it is very careful for the specimen preparation. Before experiment, they were machined by electrical discharge machining for the specimen size as large as possible. And then their cross sections were tightly glued on a metal plate together using wax. Subsequently, mechanical grinding was applied to the opposite side until the only weld and HAZ regions were left. X-ray spectra were collected in the $2 \theta$ range from $20^{\circ}$ to $85^{\circ}$ with a scan rate of $0.5^{\circ} \mathrm{min}^{-1}$.

Prior to preparing the corrosion specimens, square specimens $(1.5 \mathrm{~cm} \times 1.5 \mathrm{~cm})$ were obtained from a welded joint. For the electrochemical tests, these specimens were embedded in Epofix resin, with an electric $\mathrm{Cu}$ wire contact fixed on the inner surface so that, after preparation, only their outer surface $(20 \mathrm{~mm} \times 20 \mathrm{~mm})$ was exposed to the aggressive solutions. This surface was mechanically polished with 2000-grit SiC paper, washed with distilled water, degreased with acetone and dried at room temperature for $24 \mathrm{~h}$. The aggressive medium was $3.5 \% \mathrm{NaCl}$ solution. Electrochemical corrosion was tested using a VMP3 analyzer with a saturated calomel electrode as the reference electrode and $\mathrm{Pt}$ electrode as the counter electrode.
Table 1 Chemical compositions of test materials (mass fraction $\%)$

\begin{tabular}{lllllllllllll}
\hline Alloy & $\mathrm{Cu}$ & $\mathrm{Li}$ & $\mathrm{Mg}$ & $\mathrm{Mn}$ & $\mathrm{Zr}$ & $\mathrm{Ti}$ & $\mathrm{Fe}$ & $\mathrm{Si}$ & $\mathrm{Zn}$ & $\mathrm{Ag}$ & $\mathrm{Ni}$ & $\mathrm{Al}$ \\
\hline AA2198 & 3.24 & 0.99 & 0.33 & $<1$ & 0.11 & 0.03 & 0.04 & 0.03 & 0.01 & 0.29 & $<1$ & Bal. \\
AA2319 & 6.0 & - & 0.21 & 0.29 & 0.19 & 0.06 & 0.3 & 0.2 & 0.1 & - & - & Bal. \\
\hline
\end{tabular}




\section{Results and Discussion}

\subsection{Microstructural Analysis}

Figure 2 shows optical micrographs of the AA2198 joint laser welded with $\mathrm{Al}-\mathrm{Cu}$ filler wire. The parent alloy in Fig. 2a shows fibrous grain structure with an average thickness of about $30 \mu \mathrm{m}$ and length of several hundred microns. AA2198 is a typical age-hardening aluminum alloy. Precipitation hardening is the main strengthening mechanism. This occurs through the formation of $\theta^{\prime}\left(\mathrm{Al}_{2-}\right.$ $\mathrm{Cu}), \delta^{\prime}\left(\mathrm{Al}_{3} \mathrm{Li}\right), T_{1}\left(\mathrm{Al}_{2} \mathrm{CuLi}\right)$ or $T_{2}\left(\mathrm{Al}_{6} \mathrm{CuLi}_{3}\right)$ and $\mathrm{S}\left(\mathrm{Al}_{2-}\right.$ $\mathrm{CuMg}$ ) precipitates dispersed in the alloy [1, 7-9]. The weld shown in Fig. $2 b$ was found to have a dendritic structure with narrow dendritic arm spacing due to rapid solidification. From the weld center to the fusion line, a columnar grain zone with a width of about $50 \mu \mathrm{m}$ is shown in Fig. 2c. The growth direction of the columnar grain is along the heat flow direction. Between the columnar grain zone and the fusion line, an equiaxed fine grain zone with a width of about $15 \mu \mathrm{m}$ was also identified because of the large supercooling there. Along the fusion line and close to the base metal, there was a wide heat-affected zone (HAZ) decorated with plenty of tiny precipitates.

In order to further identify the phase distribution, X-ray diffraction was conducted as shown in Fig. 3. In the weld, $\theta^{\prime}, \delta(\mathrm{AlLi})$ and $T_{2}\left(\mathrm{Al}_{6} \mathrm{CuLi}_{3}\right)$ were the main precipitates, whereas, in parent alloy and HAZ, besides $\theta^{\prime}, \delta$ and $T_{2}$, a small amount of other precipitates including $\mathrm{Al}_{3} \mathrm{Li}_{2} \mathrm{Si}_{4}$, $\mathrm{Al}_{8} \mathrm{Mn}_{5}$ and AlLiSi were also found. A small quantity of the precipitates in the weld also implies the lower hardness and tensile strength than those of the base metal [6]. HRTEM of the parent alloy (Fig. 4a) shows the densely distributed dark structure presenting an aciculate and granular shape with tens to hundreds of nanometers in diameter. Meanwhile, a plenty of dislocations were found due to the extensive plastic deformation and flow of materials during rolling. The selected area electron diffraction shows that the light area is $\alpha-\mathrm{Al}$ with [001] direction (Fig. 4b). The dark structure is identified as a

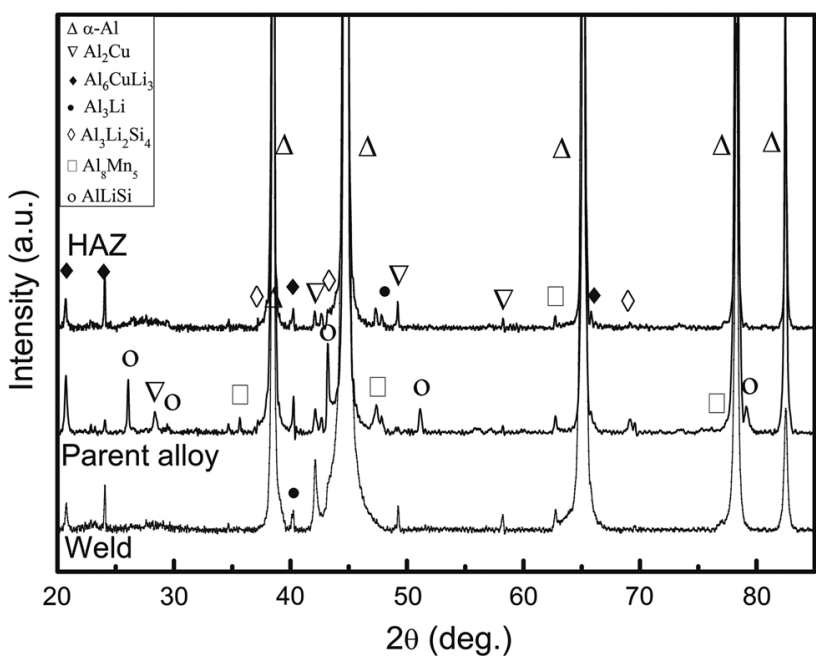

Fig. 3 XRD patterns of AA2198-T851 plate, weld and HAZ using fiber laser welding with $\mathrm{Al}-\mathrm{Cu}$ filler wire

hexagonal structure with [011] direction (Fig. 4c). The lattice constants of a and c were $4.97 \AA$ and $9.35 \AA$, respectively, which corresponds to $T_{1}$ precipitate. Around the main diffraction spot, plenty of vaguely visible satellite spots were also found. The literature has reported that the addition of $\mathrm{Cu}$ to $\mathrm{Al}-\mathrm{Li}$ alloy promoted the precipitation of $T_{1}$ and $\theta^{\prime}$ phases [10, 11]. Cavaliere et al. [12] also found the $\delta^{\prime}$ phase in 2198-T851 aluminum alloy. In our study, precipitates of $T_{2}$ and $\mathrm{Al}_{8} \mathrm{Mn}_{5}$ are also found besides of $T_{1}$, $\theta^{\prime}$ and $\delta^{\prime}$ phases. The formation of the $T_{1}, T_{2}, \theta^{\prime}$ and $\delta^{\prime}$ phases in aluminum alloys greatly increases their mechanical properties [2]. Meanwhile, these phases also accelerate the occurrence of corrosion [11]. This also implies the complicated corrosion mechanism.

High strength is achieved in aircraft aluminum alloys with the use of $\mathrm{Cu}$ as an alloying element; therefore, $\mathrm{Al}-\mathrm{Cu}$ filler is usually used to increase the strength of a welding joint. However, the distribution of $\mathrm{Cu}$ will directly affect the corrosion properties of the joint. Figure 5 shows the EDX face scanning mapping of $\mathrm{Al}$ and $\mathrm{Cu}$ in AA2198 weld with $\mathrm{Al}-\mathrm{Cu}$ filler wire using fiber laser welding. The results indicate that the distribution of $\mathrm{Cu}$ in the weld was
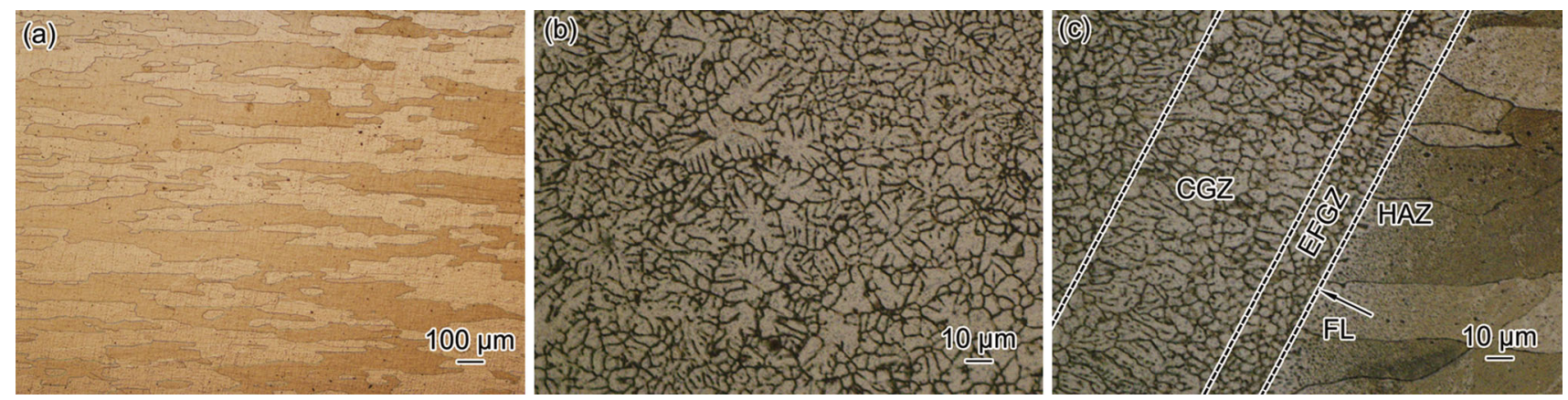

Fig. 2 Optical micrographs of a AA2198 parent alloy, b weld with AA2319 Al-Cu filler, c interface between weld and parent alloy 


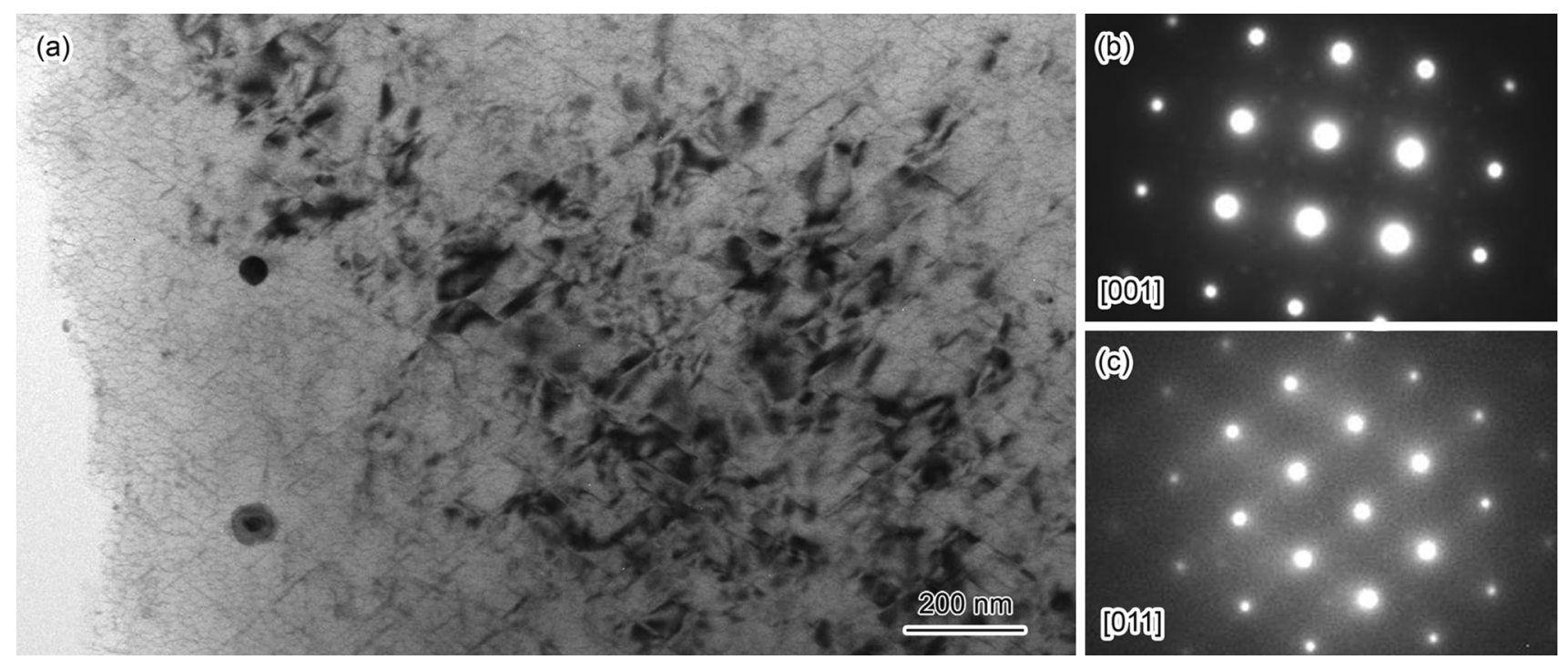

Fig. 4 TEM result of AA2198-T851 plate material showing a bright field structure; b SAED spot in bright area; $\mathbf{c}$ SAED spot in dark area

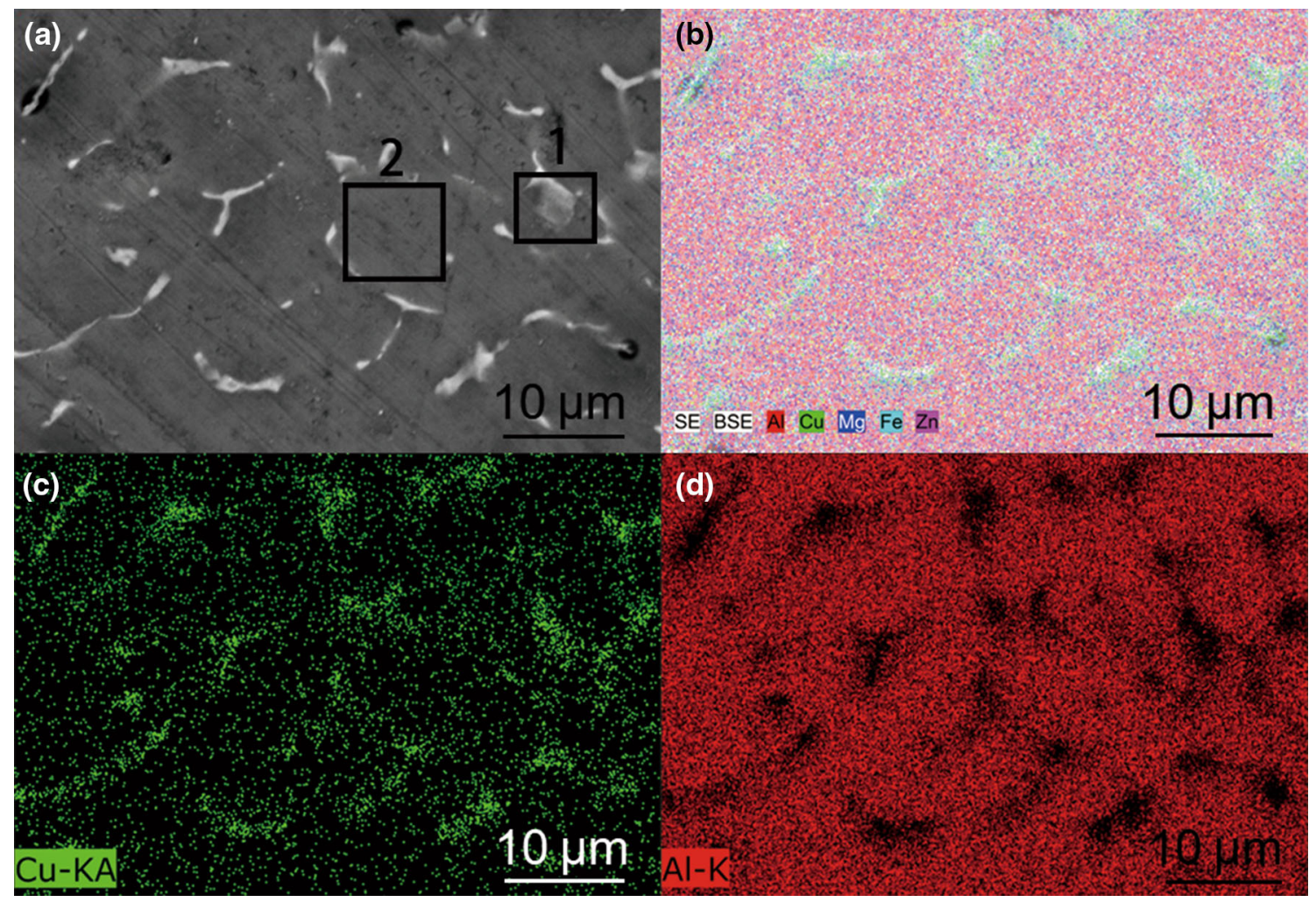

Fig. 5 EDS mapping of AA2198 weld, a SEM image, b element distribution, c Cu mapping, d Al mapping

inhomogeneous. From Table 2, we can clearly see that the light zone (see square 1) consists of plenty of $\mathrm{Cu}$ (about $13 \% \mathrm{Cu}$ ), whereas the dark zone (square 2) is mainly composed of $\mathrm{Al}$, only about $0.7 \% \mathrm{Cu}$. From these results, it is clear that plenty of $\mathrm{Cu}$ was distributed on the dendritic boundary. Rapid solidification during laser welding caused the strengthening phases containing $\mathrm{Cu}$, such as $T_{1}, T_{2}$ and $\theta^{\prime}$, to precipitate, particularly along the dendritic boundaries. Kim and Lee [13] also demonstrated the directionality of the strengthening effect associated with the $T_{1}$ phase, and finally, it affects the tensile properties.

Figure 6a shows a representative transmission electron microscope image of a weld. From the bright field image, there were not observed precipitates in the substrate of 
Table 2 Element contents detected by EDS

\begin{tabular}{llllll}
\hline & $\mathrm{Al}$ & $\mathrm{Cu}$ & $\mathrm{Mg}$ & $\mathrm{Fe}$ & $\mathrm{Zn}$ \\
\hline Light zone & 84.76 & 13.57 & 1.26 & 0.21 & 0.20 \\
Dark zone & 97.96 & 0.67 & 1.10 & 0.13 & 0.14 \\
\hline
\end{tabular}

weld. This result is consistent with that in the XRD. The majority of chemical elements in the grain boundary (Fig. 6b) and intracrystalline are (Fig. 6c) $\mathrm{Al}, \mathrm{Cu}, \mathrm{Mg}$, and Fe. As shown in Fig. 6b, the high value of $\mathrm{Cu}$ spectrum in the grain boundary implied high $\mathrm{Cu}$ content. From the selected area electron diffraction (inset of Fig. 6a), the $\theta^{\prime}$ phase with [112] direction was identified. The precipitates with high $\mathrm{Cu}$ content distributed along the dendritic boundary in the weld were responsible for the high electrode potential there.

\subsection{Corrosion Behavior of AA2198 Joint After Laser Welding}

Figure 7 shows the macroscopic corrosion morphology of an AA2198 joint after immersion in $3.5 \% \mathrm{NaCl}$ solution for 5 days. The base metal (Fig. 7a) contains big pits with wide diameter. In comparison, HAZ presented good corrosion resistance with a compact protective film. Weld shows big corrosive cracks locally that passed through the whole weld (Fig. 7b).

Different corrosion characteristics in the base metal, weld and HAZ are associated with the microstructure and chemical distribution. Figure 8 shows the microscopic corrosion morphologies of different regions in the AA2198 joint. From these figures, distinctive pit morphologies could be seen. After immersion in $3.5 \% \mathrm{NaCl}$ solution for $4 \mathrm{~h}$ (Fig. 8a), the surface of the AA2198 base metal showed plenty of pits. This is corrosion along the dendritic boundaries of the weld (Fig. 8b). Serious corrosive attack occurred at the dendritic boundaries with dissolution phenomenon occurring in places (inset) when the immersion time was increased to 5 days (Fig. 8b). In HAZ, small, densely distributed pits were found in immersion for $4 \mathrm{~h}$ compared with the parent metal (Fig. 8c).

Interestingly, the morphology of pits in the eroded surface of the parent alloy was very different from the fibrous grain structure of the parent alloy. Two kinds of pit were identified based on their $\mathrm{Cu}$ content. One (labeled 1) had a sandwich structure with bright center and black outer; the other (labeled 2) showed typical pitting corrosion. According to the EDX results, the sandwich's bright center was enriched with $\mathrm{Cu}$. The pits labeled as 2 were identified as the phase with low $\mathrm{Cu}$. But, Li was undetected. This implies that $\theta^{\prime}, \delta$ and $T_{2}$ precipitates in the base metal were responsible for the pits initiation. In comparison, weld showed corrosion at the dendritic boundaries when it was immersed in $3.5 \% \mathrm{NaCl}$ solution for $4 \mathrm{~h}$. Rapid solidification during laser welding enriched the eutectic structure $\theta^{\prime}$ phase and other precipitates along the dendritic boundaries. $\mathrm{Cu}$ was therefore particularly deleterious to the corrosion behavior of $\mathrm{Al}$ alloys owing to the Galvanic couples setup between $\mathrm{Cu}$-rich intermetallic particles and the
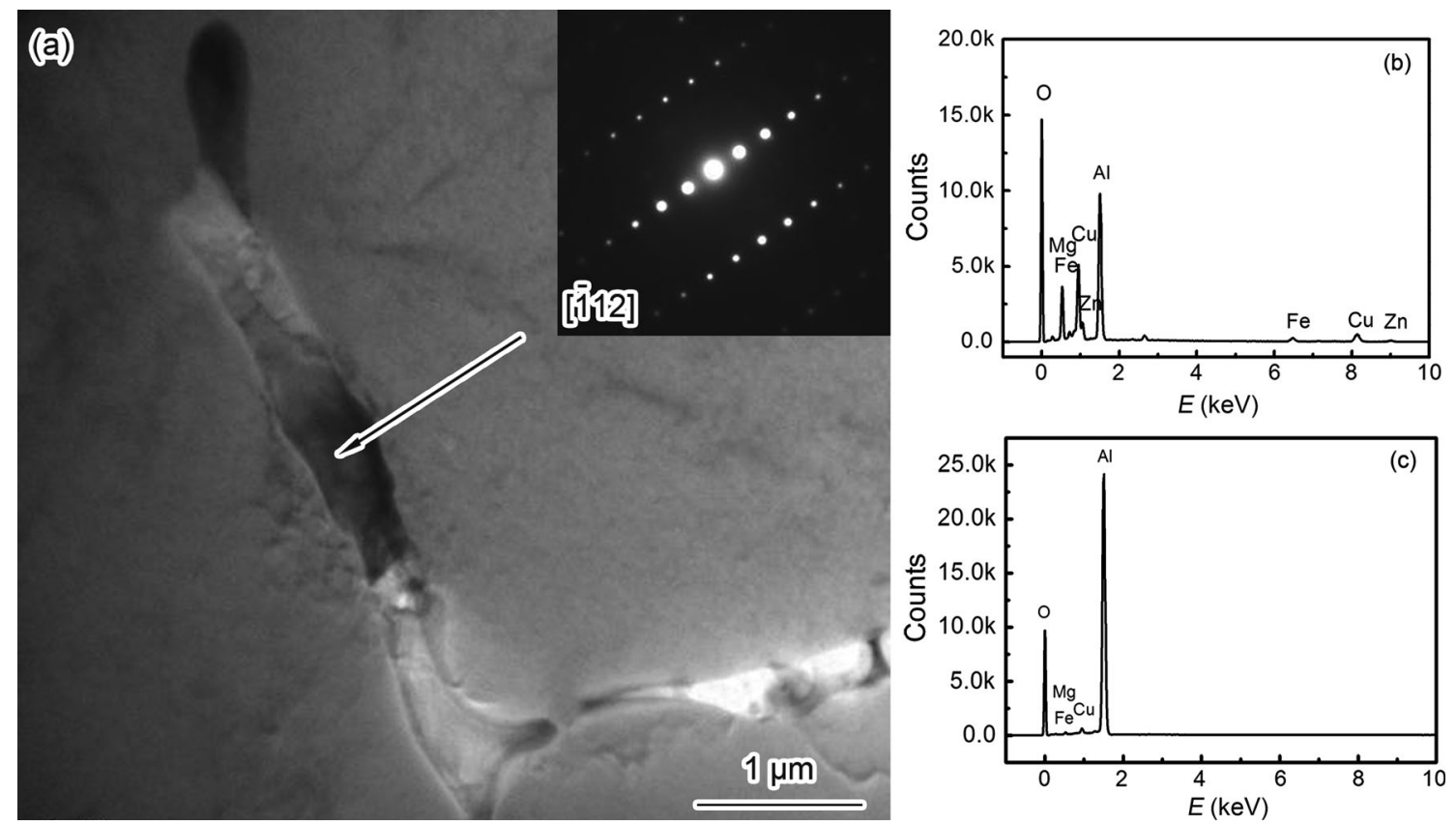

Fig. 6 a TEM image of the weld with AA2319 Al-Cu filler wire, b element spectrum in the grain boundary, c element spectrum in intracrystalline 

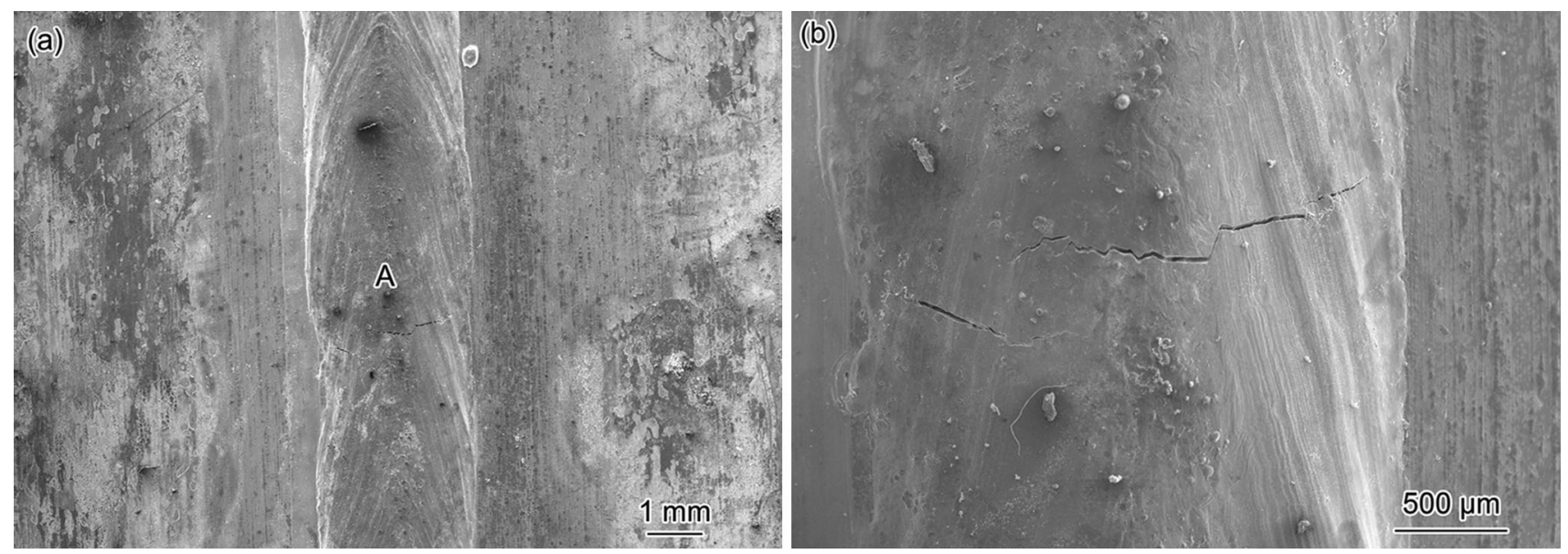

Fig. 7 a Macrostructure of AA2198 joint after immersion in $3.5 \mathrm{wt} \% \mathrm{NaCl}$ solution for 5 days, $\mathbf{b}$ enlarged view in the site A
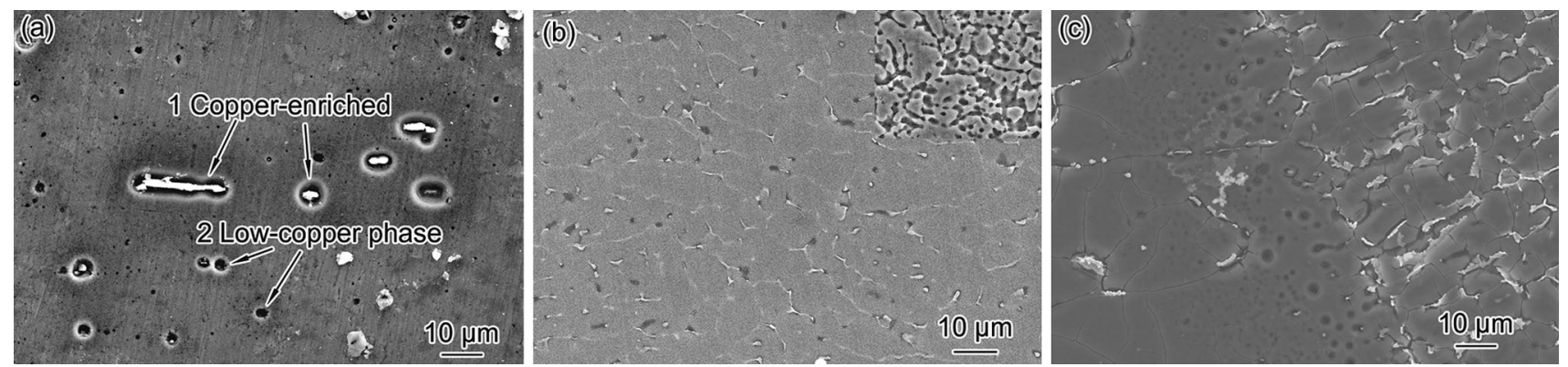

Fig. 8 SEM images showing corrosion morphology of joint in $3.5 \mathrm{wt} \% \mathrm{NaCl}$ solution: a parent alloy for $4 \mathrm{~h}$, b weld for $4 \mathrm{~h}$, the inset for 5 days, c HAZ for $4 \mathrm{~h}$

adjacent $\mathrm{Cu}$-depleted matrix. Enriched $\mathrm{Cu}$ particles at the dendritic boundaries acted as the cathode compared with the $\mathrm{Al}$ base when immersed in the electrolyte, leading to the preferential creation of Galvanic cells along the dendritic boundaries. Increasing the immersion time to 4 days, there was obvious corrosion at the weld's dendritic boundaries (Fig. 8b, inset) and a macroscopic crack was observed in the surface (Fig. 7). Meanwhile, cathodic reactivity was found in a form of grooves around the dendritic boundary. HAZ showed different corrosion morphology. During laser welding, HAZ experienced solid-state phase transformation, leading to the formation of plenty of the precipitates. In the initial immersion for $4 \mathrm{~h}$, a lot of small pits were created due to the Galvanic cell between the precipitates and the $\mathrm{Al}$ base.

Figure 9 compares the impedance responses of the parent alloy with weld. The data reveal that the impedance diagram of the parent alloy consisted of a large capacitive loop at high frequencies and a small inductive one at low frequencies during the initial 2-h immersion. When the immersion time increased to more than $2 \mathrm{~h}$, only the capacitive loop was observed. The weld had a large capacitive loop at both high and low frequencies. The bigger diameter of the capacitive loop in weld reflected the higher impedance value.

The inductive loop in the parent alloy may be attributed to the relaxation process of the oxide presenting on the electrode's surface, which was obtained by the adsorption of the species such as $\mathrm{Cl}_{\text {ads }}^{-}$and $\mathrm{H}_{\text {ads }}^{+}$[14]. This was consistent with the proposed mechanism of chemisorption of $\mathrm{Cl}^{-}$ions onto the oxide surface forming an oxide-chloride complex [15]. This complex exhibits fast dissolution in the presence of $\mathrm{H}^{+}$. Similar findings were reported by Lenderink et al. [16] during the corrosion of pure $\mathrm{Al}$ in acidic solutions containing chloride ions. Some authors [17, 18] also think that the inductive loop exists in the early stage of pitting corrosion, consistent with the results of this experiment. With corrosion proceeding, the oxide film is considered to be the parallel circuit of a resistor due to ionic conduction in the oxide film and a capacitor due to its dielectric properties. The impedance response presents the capacitive loop both in high and low frequencies. The electrode impedance in this case was determined by the metal-oxide interface, the oxide film and the oxide-solution interface. At this time, a high-frequency and low-frequency capacitive loop could be assigned to the relaxation 

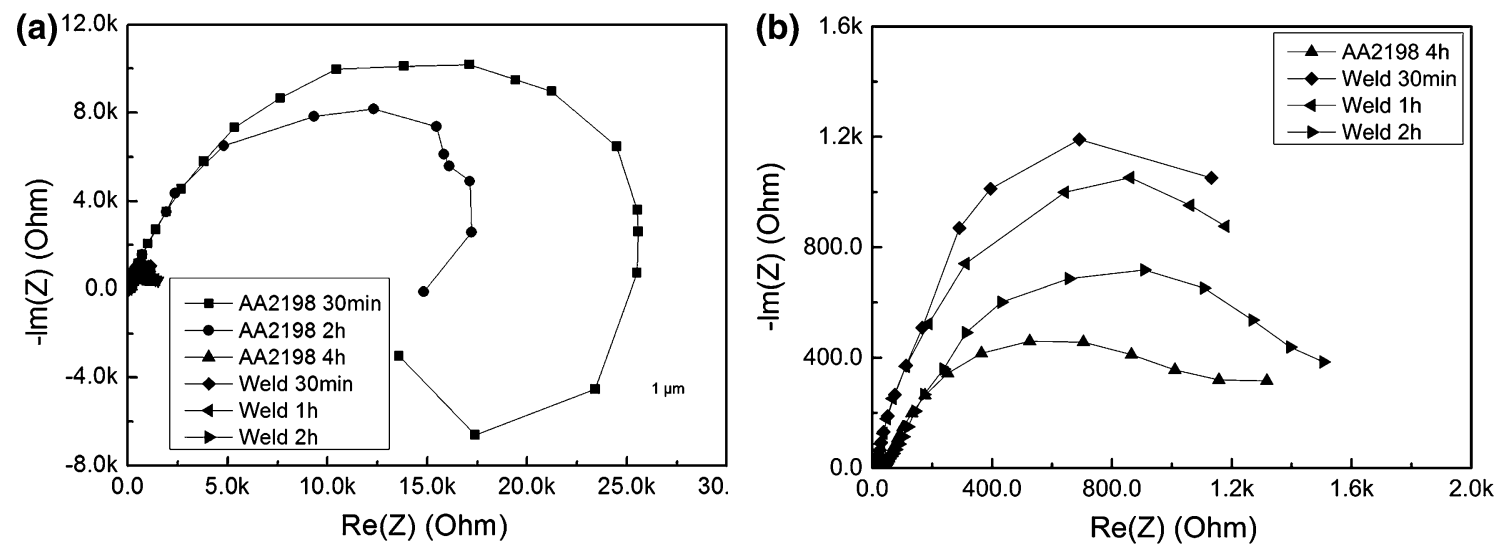

Fig. 9 a EIS of AA2198 parent alloy and the weld after immersing in $3.5 \mathrm{wt} \% \mathrm{NaCl}$ solution, $\mathbf{b}$ the partial magnification picture in a

process due to the natural oxide present on the surface of the aluminum alloy samples and its dielectric properties.

\section{Conclusions}

Aluminum alloy is a hard-to-weld metal material using laser welding due to the high reflectivity of aluminum to laser and low joint strength. Light alloy with the addition of a small proportion of Li can improve the alloy's strength. Studying the corrosion behavior of an AA2198-T851 joint welded with $\mathrm{Al}-\mathrm{Cu}$ filler wire using fiber laser welding, the following conclusions can be drawn:

1. The AA2198 parent alloy is composed of large elongated structures with fine $T_{1}, T_{2}, \theta^{\prime}$ and $\delta^{\prime}$ precipitates. In weld using fiber laser welding with an $\mathrm{Al}-\mathrm{Cu}$ filler, very fine dendritic structures with narrow dendrite spaces were observed. The addition of $\mathrm{Al}-\mathrm{Cu}$ filler induced the inhomogeneous distribution of $\mathrm{Cu}$ due to rapid solidification during laser welding. $\mathrm{Cu}$ was mainly distributed along the grain boundaries. HAZ had plenty of tiny precipitates.

2. The AA2198 parent alloy showed pitting corrosion behavior in $3.5 \% \mathrm{NaCl}$ solution. Two kinds of pits were identified depending on the chemical species in the precipitates. In the precipitates containing $\mathrm{Cu}$, such as $T_{1}$ and $\theta^{\prime}$ phases, electrode transfer happened during corrosion; therefore, sandwich corrosion morphology was observed. In the precipitates not containing $\mathrm{Cu}$, there was pitting corrosion. Weld showed dendritic boundary corrosion behavior, and when immersed in solution for a long time, some big cracks appeared. HAZ presented favorable corrosion resistance.

3. Electrochemical impedance spectroscopy measurements showed that parent alloy had an inductive effect in initial corrosion in $3.5 \% \mathrm{NaCl}$ solution due to the pitting effect and weld had a large capacitive loop at both high and low frequencies.

Acknowledgements This work was financially supported by the National Natural Science Foundation of China (Grant Number: 51505010) and Beijing Natural Science Foundation (Grant Number: 2152007).

\section{References}

[1] A.J. Beaudoin, M. Obstalecki, W. Tayon, M. Hemquist, R. Mudrock, P. Kenesei, U. Lienert, Acta Mater. 61, 3456 (2013)

[2] R.J. Rioja, Mater. Sci. Eng., A 257, 100 (1998)

[3] K.L. Lin, W.X. Yang, J.X. Lu, R.S. Xiao, Chin. J. Lasers 41(1), 0103007 (2014). (in Chinese)

[4] S.K. Yin, J.X. Lu, R.S. Xiao, Chin. J. Lasers 43(4), 0403007 (2016). (in Chinese)

[5] International Alloy Phase Diagram and the Handbook Committee, in ASM Handbook: Vol. 3 Alloy Phase Diagram (1992)

[6] K.L. Lin, W.X. Yang, T. Huang, R.S. Xiao, Acta Opt. Sin. 35(A02), 153 (2015). (in Chinese)

[7] J.F. Li, C.X. Li, Z.W. Peng, W.J. Chen, Z.Q. Zheng, J. Alloys Compd. 460, 688 (2008)

[8] R. Yoshimura, T.J. Konno, E. Abe, K. Hiraga, Acta Mater. 51, 2891 (2003)

[9] H.Y. Li, Y. Tang, Z.D. Zeng, Z.Q. Zheng, F. Zheng, Mater. Sci. Eng., A 498, 314 (2008)

[10] A. Balbo, A. Frignani, V. Grassi, F. Zucchi, Corros. Sci. 73, 80 (2013)

[11] J. Kang, R.D. Fu, G.H. Luan, C.L. Dong, M. He, Corros. Sci. 52, $620(2010)$

[12] P. Cavaliera, M. Cabibbo, F. Panella, A. Squillace, Mater. Des. 30(9), 3622 (2009)

[13] N.J. Kim, E.W. Lee, Acta Metall. Mater. 41, 941 (1993)

[14] S.S.A.E. Rehim, H.H. Hassan, M.A. Amin, Corros. Sci. 46, 5 (2004)

[15] L. Garrigues, N. Pebere, F. Dabosi, Electrochim. Acta 41, 1209 (1996)

[16] H.J.W. Lenderink, M.V.D. Linden, J.H.W.D. Wit, Electrochim. Acta 38, 1989 (1993)

[17] M. Keddam, C. Kuntz, H. Takenouti, D. Schuster, D. Zuili, Electrochim. Acta 42, 87 (1997)

[18] A. Conde, J. Damborenea, Corros. Sci. 42, 1363 (2000) 